\title{
A Study on the Dialectical Relationship Between Vocal Performance and Teaching
}

Chuanzhi Zhong

Department of music, Nanchang Normal University

\author{
Keywords: Vocal Performance; Teaching; Unity of Opposites; Dialectical Relationship
}

\begin{abstract}
This paper analyzes and presents the dialectical relationship between vocal performance and teaching based on the internal contradictions from a development perspective according to the law of universal connection and the dialectical view. There are many unities of opposites in the vocal performance and teaching. Without understanding of these relationships, people cannot deal with them correctly. As a result, it is hard to conduct the complete process of performance and the desired effects. This paper defines the unities of opposites and dialectical relationship and describes that the dialectical cognition of these relationships plays positive roles in the vocal performance and teaching, so that people can accurately grasp the singing skills, express their emotions, and better understand the unities of opposites and dialectical relationship. At a macro level, people can get a comprehensive understanding of the vocal performance and teaching, deal with the problems in the process of vocal performance and teaching, and thus improve the vocal performance and teaching level.
\end{abstract}

\section{Introduction}

The vocal performance and teaching are two practical activities of music art. In the vocal performance and teaching, the unity of opposites and dialectical relationship are usually ignored. Therefore, it is both necessary and important to study the relationships. There are many contradictions in the vocal performance and teaching. People cannot grasp and deal with the problems correctly before they understand the dialectical relationship. As a result, it is hard to achieve the desired effects.

vocal music practice is an organic whole, and every vocal music worker and student should pay attention to several units of dialectical relationship, because it is hardly to perform perfectly without active coordination. Therefore, singers must grasp the unity of opposites and dialectical relationship, get a comprehensive understanding of the vocal music practice, thus grasp the vocal music from the whole, and learn the vocal music with a clear direction and idea.

As a graduate of vocal performance and teaching major, the author suggests the singer shall first understand the dialectical relationship in the process of singing, studies how to deal with the dialectical relationship, how to define the concept, how to adjust the body, and thus sing in a correct and scientific manner. In the process of vocal performance and teaching, teachers should define a clear bilateral relationship, grasp the methods of solving various contradictions in the teaching, reduce the potential issues; make students get the optimal physical and psychological states, teach students with their aptitudes, and thus achieve the desired effect. 


\section{Theoretical Basis of Research on Dialectical Relationship between Vocal Performance and Teaching}

Everything is composed of contradictions and fights, and they penetrate throughout the development process. Contradiction is the difference between various aspects and various locals caused by the development of things. Every aspect or local is relatively independent, so the contradiction is the difference between all things, and difference lead to fights. The purpose of fighting is to eliminate all the differences. Therefore, contradictions and fights are powerful motive force for the development of things.

In a similar way, any art is composed of various contradictions. The various contradictions and contradictory forces are relatively unbalanced, including the vocal music. Therefore, it is particularly important to deal with the dialectical relationship between vocal performance and teaching, flexibly apply to the vocal performance and teaching.

Niversality of Contradictions. As is known to all, the process of vocal music learning is the continuous transformation and solution of various contradictions in the vocal music. From the transformation of vocal music teaching stage or process, at the early stage of vocal music learning, vocal teachers may seize the main contradiction - "breath". However as time goes by, after the main contradiction of "breath" is solved, breath will no longer be a main contradiction, a new contradiction between "breath" and "sound" becomes the main contradiction. If the student gets better sound based on better breath, then he must solve the main contradiction between "sound" and "emotion". After solving this contradiction, there will also be more requirements on performance and culture cultivation, and they form a variety of contradictions. Thus, the process of vocal music learning is the transformation and alternate solution of contradictions. Different students have different contradictions at different phases. Every aspect related to vocal teaching has various opposites. In the learning of vocal psychology and physiology, there are psychological and physiological contradictions as well as subjective and objective contradictions. In the learning of vocal skills, there are contradictions of breath-in and breath-out, breath and sound, sound and emotion, words and chamber, back and front, large and small, whole and part, bright and dark, true and false, top and bottom, and so on. In the work processing, there are contradictions of fast and slow, strong and weak, rise and fall of emotion, and so on. In vocal teaching, there are contradictions of teaching and learning, teachers and students, and so on.

In a conclusion, there are many contradictions between vocal performance and teaching. These contradictions are universal.

Dialectical View. Why look at problems from a dialectical view?

Firstly, dialectical view conforms to the law of vocal music development. Everything has mutual exclusion and interdependence, namely, there is duality between things, and this is the essence of Marx Philosophy. Like many other things, vocal music also has duality. For example, it has the duality of breath-in and breath-out, sound-front and sound-back, breath and sound, sound and emotion, internal and external factors, bright and dark and so on. The duality principle stresses to deal with problems from the dialectical view. Instead of a subjective assumption artificially imposing to vocal music, it is an inherent duality of vocal music itself, and it requires vocal music learners to analyze the problems according to the nature of vocal music. Only in this way, people can grasp the law of vocal music and promote the development of vocal music. Therefore, dialectical view in the vocal music teaching refers to deal with problems practically and realistically in the vocal music teaching, and proceed from reality of vocal music, which conforms to the law of vocal music. 
Secondly, vocal teaching practice proves that it is scientific to take the dialectical view to observe and analyze the vocal music problems in vocal teaching. In fact, during the process of vocal music development, there are many successful vocal teaching practices from the dialectical view. For some successful examples that the vocal music circle analyzes and solves the vocal music problems from the dialectical view, "China's Caruso" - Professor Shen Xiang, a world famous singer and vocal music educator who had cultivated many renowned singers, was recorded, "Since 1980, the cooperative teaching of Shen Xiang and Li Jinwei has achieved good teaching effect. Many of their students have won the prizes in international vocal competitions. Seven students in five parts have won the international prizes during the several years, and this is really rare in the global vocal music." according to the memory of his student, there are dialectical views in his teaching for dealing with the psychological and physiological contradictions, sound-front and sound-back contradictions, fast-process and slow-process contradictions, sound-strong and sound-weak and so on.

Therefore, it is theoretically scientific and practical to adopt the dialectical view and deal with vocal music teaching problems. Meanwhile, it is a feasible dialectical thinking method in vocal teaching which deserves a promotion.

The dialectical relationship objectively exists in vocal performance, some are in the consolidation of singing state, some are in the understanding and performance of works, and others are penetrated throughout the whole process from the consolidation of singing state to the performance of art works. These contradictions are complicated and it is difficult to recognize in a short time. However, without understanding the dialectical relationship between these contradictions or correctly handling these relationships, it will be hard to smoothly carry out the process from consolidation of singing state to the complete performance of works. Therefore, these contradictions should not be analyzed by separating them. Only by analyzing and demonstrating the contradictions in the vocal performance as well as the relationships between parts and between part and whole can students completely understand the vocal performance, master it from local to whole, and form a clear direction and idea for the vocal art learning.

How to Deal with the Contradictions between High and Low Singing Resonance Positions. High position means to sing at a high resonance position. Each vocal teacher requires to unify the sounds in all vocal zones at the head cavity for resonance, namely, the face mask, so as to achieve the bright, centralized, loose and smooth sound effect. Low position, on one hand, means that the throat position shall be relatively low, because the throat opening is a very important link of singing. Only by putting the throat at the lowest position of breath-in can open the throat and remain a relative stable and lasting state. On the other hand, low position means low breath fulcrum. Breath is the most important. There is a saying in Italy "master breath, sing well." Breath is the power of singing. A nice sound comes from "breath in the lower belly". There is a support for breathing. It is used as the core power to control the breath movement and produce the force downwards, thus sound is made at a high resonance position. Also it is described as "deep breath, power sound."

How to Deal with Large Cavities and Small Cavities. The most important thing of singing is to fully mobilize each resonance cavity of the body, and thus obtain full sound and softer color. People have to organically combine with the head cavity, thoracic cavity, nasal cavity, oral cavity and the abdominal cavity into a unity for singing, like a columnar box. Therefore, the resonance of singing is related to the tone, volume and expression, so as to actively mobilize each resonance cavity, and perfect resonance is an important means of singing. Meanwhile, a singer must dedicate his entire emotion to the songs and make full use of the body resonance. In this way, singers can build specific 
image and artistic conception in the singing performance, form full appeal, and finally achieve the perfect art performance. Scientific resonance requires harmonious sound, in order to achieve the effects of rich color, strong stereoscopic sensation and pleasant voice. Therefore, it is essential for the singer to understand the resonance cavity, and adjust the resonance cavity.

The singing resonance consists of chest resonance, oropharyngeal cavity resonance, nasal resonance and head resonance.

How to deal with contradictions between deep-breath and shallow breath. Breath is the power of singing. The Western bel canto emphasizes a deep breath, while the traditional Chinese singing emphasizes "breath in the lower belly". It is certainly that the two are exactly same because they all emphasize the importance of breath. However, they differ greatly in the practical application. It is said that take a deep breath in singing. That's true, but it is not absolute deep, because nobody can breathe into "the lower belly" or other deeper places. Deep and shallow breath is a kind of feeling. It cannot be separated from the singing technique and singing style. Many vocal teachers believe the reason why students sing badly is that they breathe too shallow, so they emphasize much on deep breath. Students also believe that they can sing well as long as they breathe deeply. As a result, some of them hold breath as deep as possible, their faces turn purple, their sounds get straight and their features become grossly offensive. Such a vocal training turns the natural and smooth breath into unnatural one, leading to stagnated breath and breath holding.

\section{Dialectical Unity in Vocal Teaching}

The Bilateral Relationship between Vocal Teaching and Vocal Learning. The main contradiction in teaching lies in teaching and learning. Which is the principal aspect of a contradiction? There are two opinions. One is that teachers play a leading role in the teaching, whereas the other is that the student is the main participant in the teaching activities. The two opinions are proposed from different aspects and each has their specific meaning. The leading role of teacher mainly means that the teaching content and the ways of learning are determined by teachers, and learning desire, interests of knowledge and learning habits depend on the correct education of teachers. For students, the teacher is a guider and a leader. As teachers play a leading role, the education and teaching activities are different from the influence of environment. The teaching subject of students means that the teaching process is students' cognition of objects, and students cultivate their wisdom, aptitude, thought and views by transforming the cognitive things into his thought in a cognitive activity. In short, in the teaching process, the educated transforms the external teaching contents into subjects themselves. Two views are not contradictory. According to the above analysis, the author believes that the main aspect of the contradiction is the teacher or the teacher's teaching. This is because the teaching of educator reflects the social requirements of a new generation. This teaching determines a new development level and direction of a new generation. The contradiction between the new teaching requirements and the physical and mental development of students is the driving force to promote the development of students. Besides, the teaching of teachers is contradictory, positive, active and progressive, whereas the learning of students is always passive, stable and conservative.

Main Contradictions and Minor Contradictions in Vocal Teaching. The main contradiction in the vocal music is the contradiction which plays a leading role among all the contradictions. As the main contradiction restricts the existence and development of other contradictions and determines the direction of the development, in the vocal teaching, the principal contradiction determines whether 
there is a clear core of vocal teaching. In the vocal teaching activities, if people cannot distinguish between main and minor contradictions among all contradictions and think everything is balanced, then they cannot understand which is more important. Obviously, this vocal teaching without understanding which is more important makes teaching become casual and will not achieve good teaching effects. On the contrary, if the main contradiction can be seized from the numerous contradictions, there will be key points in the vocal music teaching, and students can gradually make progress in vocal teaching.

The Spiral Progress of the Students and the Motivation of Teachers in Vocal Teaching. The process of learning singing is not always successful, because the singing is abstract. It takes a long-term practice to form the singing skills. Not everyone is the same, some people make progress quickly at the beginning, and then gradually slow down; some people make progress slowly at the beginning, but later make quick progress. Few people can maintain the same speed without big changes in the practical progress. Regardless of what kind of practice it is, its processes are not always forward. After a period of time, it is possible to meet stagnation or even backward phenomenon. It is known as the "plateau phenomenon", which is a special development period from quantitative change to qualitative change in the vocal music learning. After going through this period, students will make obvious progress. However, it is difficult to break through this period, and all previous efforts will be wasted without persistence. The duration of plateau phenomenon varies with each individual, so teachers and students shall adjust their attitudes for a active response.

\section{How to Deal with the Contradictions in Vocal Performance and Teaching}

The Principle of Gradual Learning. People all understand "one meal won't make a fat man", but the phenomenon still exists in teaching. Comparing with classmates, the students wants to develop without solid base. Some sing hard songs, he follows. Teachers can't withstand the pressure and make concessions. However, for poor students, teachers shall require them to adapt to and cooperate at each stage. If a stage does not actually end, and he is forced to accept another stage of learning, he will be confused and have wrong understanding, and thus the learning becomes slow instead of quickness. If breathing is still very weak, overemphasis on releasing the throat will result in heavy head. Practicing weak sound before strong sound makes the weak sound become more tremble, lifted and false.

Of course, the quantitative changes cause the qualitative change, and a big progress can be made within a short term. However, the mature development requires a relative stable consolidation stage. If it takes a limited time for the teacher to teach a student, such as two years, three years or four years, focus on his lifetime occupational development, lay a solid foundation, stimulate him, is not eager to let him sing perfect during teaching, or is not eager to make students brilliant on the stage. In such a way, when the next teacher takes over, he will slowly feel the roles of your foundation, and show sincere gratitude and appreciation.

The Principle of Performance and Art Combination. Arts and skills, namely sound and emotion, are closely related two parts of the singing. The vocalization, articulation, pronunciation and emotional expression are integral parts of singing, which are inseparable. Singing takes the whole human body as the musical instrument, which cannot be completed only by voice, breath or resonance. Singing is a performance art involving mind and body, including the soul. Singing should be a soul-stirring perfect art with integration of various factors. In other words, only by performing 
skillfully with beautiful voices and deep feeling and combining arts with skills can the singing touches people's hearts and achieve the ideal artistic achievements.

Art creation, artistic requirements, artistic imagination and artistic realm are masters, and these factors play dominant roles. The basic skills and techniques serve the art, which are means to reflect the artistic effects. When teaching skills to students, do not purely emphasize the techniques, but instead, teach students to "sing in a heartfelt manner", learn to express emotions with "heart", drive voices with emotion, and infect students with music, so as to promote their skills. Practice has proved that the techniques is consistent with art exercise, even if they are conducted separately, they promote each other and interact as both cause and effect. The technical capability may be improved by the performance of song, and the requirements of song performance can be achieved more accurately through the technical exercise. In the primary stage of the teaching, it is easy to ignore the artistic requirements, and take a one-sided approach to focus on technical training. At the later stage of teaching, it is easy to emphasize the artistic performance and not pay attention to technical training. These two practices are harmful, which will inevitably affect the coordinated and unified technical and artistic development of students.

In teaching, the teacher should always closely link them together. Although a point can be sometimes highlighted, the unity of singing must always be returned. For example, though breath is the basis of singing, but it cannot purely train breath without considering the overall demands on voice organs, and students should train with combination of sounds. Sometimes, the sound might be trained from the perspective of breath, or test whether the breath application is correct through the sound effect.

\section{Conclusions}

This paper adopts the relevant principle of materialist dialectics, and presents the problems existing in the unity of opposites during the vocal performance and teaching. The study strives to analyze the specific dialectical relationship between vocal performance and teaching by using the dialectical thinking method, reveals its essential law, and enlightens the dialectical thinking method for vocal learners and vocal teachers. Based on analysis, sorting and summary of previous studies, this paper mainly makes the following cognitive achievements:

1. The author analyzes and presents the dialectical relationship between vocal performance and teaching based on the internal contradictions from a development perspective according to the law of universal connection and the dialectical view. Understand and solve the problems in the process of vocal performance and teaching, and thus improve the vocal performance and teaching level.

2. The author defines the dialectical relationship and describes that the dialectical cognition of these relationships plays positive roles in the vocal performance and teaching, so as to accurately grasp the learning of singing skills and expression of their singing emotions.

3. To solve the dialectical relationship between all contradictions in the vocal performance and training, this paper specifically analyzes the dialectical relationship between these contradictions, adopts the dialectical view, and proposes the principles for compliance. 


\section{Acknowledgment}

Research Project in Teaching Reform of Jiangxi Colleges and Universities: Research on Training of Music Teachers in the Rural Primary and Secondary Schools in Jiangxi National Training Plan, Project No.: JXJG-14-23-7

\section{References}

[1] Tang Lin. Discussion on Vocal Music Teaching [M] Shanghai Conservatory of Music Press, August 2004, Shanghai

[2] Zhao Zhenmin. Vocal Music Theory and Teaching [M] Shanghai Music Publishing House, March 2002, Shanghai

[3] Luo Yiqi. Vocal Music Art and Practice [M] Shanghai Jiaotong University Press, September 2005, Shanghai

[4] Huang Youkui. Singing Art [M] Hunan Art Publishing House, May 1989, Changsha

[5] Zhao Shuyun. Singing Art and Practice [M] Zhejiang University Press, September 2001, Hangzhou

[6] Yu Yixuan. Yu Yixuan Vocal Arts [M] Chinese Music Publishing House, July 2004, Beijing

[7] Li Dazhu. Outline of Materialist Dialectics [M] Wuhan University Press, April 2007, Wuhan

[8] Basic Principles of Marxist Philosophy of Compilation Group in Shanghai Universities. Basic Principles of Marxist Philosophy [M] Shanghai People's Publishing House, July 1980, Shanghai

[9] Li Jinwei and Li Jinyuan. Shen Xiang Vocal Education Art [M] Chinese Music Publishing House, February 2003, Beijing

[10] Shang Jiaxiang. History of Vocal Development in Europe [M] Chinese Music Publishing House, 2003, Beijing

[11] Gongsun Nizi, Record of Music [M] People's Music Publishing House, 1958, Beijing 